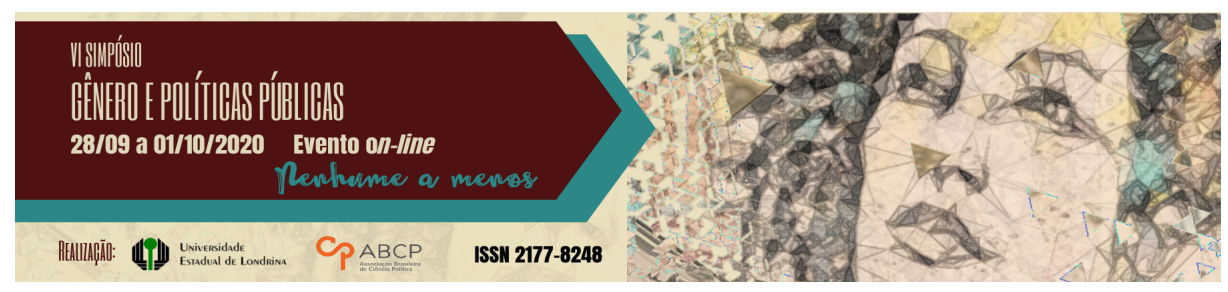

\title{
Eros e as mulheres nas educações para a ciência no Antropoceno
}

\author{
Bruna Adriane Fary ${ }^{1}$; Angela Marta Pereira das Dores Savioli²
}

\section{Resumo}

Este texto trata a respeito das urgências de pensar a "Agonia de Eros" nas educações frente à problemática do Antropoceno, era em que a humanidade se torna uma força geológica, capaz de alterar ciclos biogeoquímicos, e consequentemente, de erosão do outro. Eros serve como metáfora para pensar a possibilidade de uma experiência do outro em sua alteridade. Para tal movimentação três eixos são abordados: a) Eros como modo de repensar as educações para ciência na contemporaneidade; b) a magia e o animismo como pulsos eróticos na disputa das educações para ciência; e c) o conhecimento de técnicas, práticas e políticas realizadas por mulheres como formas de resistir a agonia de Eros, ou seja, a narcisificação do si. Como resultados, mostra-se o cuidado com a natureza, com o outro, por meio da força do feminino, do coletivo, contribuindo para refletir nas educações para a ciência na era do Antropoceno.

Palavras-chave: Educação Ambiental, Ecofeminismo, Ensino de Ciências

\section{Eros and women in science educations in the Anthropocene}

\footnotetext{
1 Universidade Estadual de Londrina. Mestra no Programa de Ensino de Ciências e Educação Matemática da Universidade Estadual de Londrina. Licenciada em Química pela Universidade Tecnológica Federal do Paraná, campus Apucarana. Professora na Educação Básica. E-mail: fary.bruna@gmail.com.

2 Universidade Estadual de Londrina. Doutora em Matemática pela Universidade de São Paulo. Bacharel em Matemática pela Universidade Estadual Paulista Júlio de Mesquita Filho. Professora associada da Universidade Estadual de Londrina. E-mail: angelamartasavioli@gmail.com.
}

GT 02 - Epistemologia feminista: reflexões no Ensino de Ciências 


\begin{abstract}
This text deals with the urgencies of thinking about the "Eros agony" in educations in the face of the problem of the Anthropocene, in which humanity becomes a geological force, capable of altering biogeochemical cycles, and, consequently, of erosion of the other. Eros serves as a metaphor for thinking about the possibility of an experience of the other in its otherness. For this movement, three axes are approached: a) Eros as a way to rethink science education in contemporary times; b) magic and animism as erotic pulses in the dispute for science education; and c) the knowledge of techniques, practices and policies carried out by women as ways to resist the agony of Eros, that is, the narcissification of the self. As a result, care with nature is shown, with the other, through the strength of the feminine, of the collective, contributing to reflect on educations for science in the Anthropocene era.
\end{abstract}

Keywords: Environmental Education, Ecofeminism, Science Teaching

\title{
Introdução
}

Este texto trata a respeito das urgências de pensar a "Agonia de Eros" nas educações em ciências frente à problemática do Antropoceno, era em que a humanidade se torna uma força geológica, capaz de alterar ciclos biogeoquímicos da Terra, e consequentemente, de erosão do outro $^{3}$. Eros serve como metáfora para pensar a possibilidade da experiência do outro em sua alteridade, daquele que não pode ser abarcado pelo regime do eu (HAN, 2017).

A Terra abriga uma diversidade de humanos e não humanos e está inserida em um período de exploração desenfreada de recursos naturais e desequilíbrios ecológicos, que reverberam no socius, no subjetivo e no ambiente (GUATTARI, 2012). A esse modo de existência de influência antropocêntrica é nomeado como Antropoceno, a Época em que as ações humanas passam a ser uma força geológica capaz de alterar as paisagens do planeta.

O Antropoceno marca o tempo do presente, da contemporaneidade ao tratar das relações entre o sistema capitalista e

3 O outro enquanto as multiespécies que de forma simpoiética compõem Gaia (HARAWAY, 2019). 
suas capturas subjetivas, recursos naturais e instâncias sociais multiespécies. Inicialmente proposto por Crutzen e Stoermer (2000) o termo enfrenta algumas resistências em aceitação por parte da comunidade científica (VEIGA, 2019). O conceito adquire espaço na medida em que se observam alterações significativas nos ciclos biogeoquímicos do planeta, na integridade da biosfera, mudanças climáticas, entre outros problemas, que ocorrem por uma combinação de fatores. Estes são alguns dos exemplos impulsionados por um sistema "produtivo-econômico-subjetivo" (GUATTARI, 2012, p. 32), o Capitalismo Mundial Integrado (CMI) (DANOWSKI; VIVEIROS DE CASTRO, 2014; GUATTARI, 2012) do qual todos que de alguma forma estão inseridos nesse sistema possuem parcela de responsabilidade socioambiental.

O período do Holoceno, Época geológica em que as condições ambientais foram favoráveis ao desenvolvimento de técnicas agrícolas, criação de centros urbanos e "domínio" da natureza, dá lugar a cena do anthropos, em que os modos de vidas modernos, por meio das ações humanas, são capazes de modificar o ambiente em que vivemos.

Estamos deixando algumas pegadas, alguns resíduos e vestígios tecnológicos, os tecnofósseis ${ }^{4}$. Ou seja, uma quantidade relevante de material não orgânico, que resiste a processos de deterioração, passíveis de caracterizar estratos do Antropoceno, como plásticos, alumínio elementar, concreto, asfalto, materiais radioativos e eletrônicos. A própria elaboração dos Limites Planetários (LP) (ROCKSTRÖM et al, 2009) é um indicativo que fornece indicadores dessa época do Antropoceno. Compreendidos e articulados, em sua complexidade, por Miranda et al (2018, p. 1994) esses limites são:

mudanças climáticas; mudança na integridade da biosfera (perda de biodiversidade e extinção de espécies), depleção da camada de ozônio estratosférico, acidificação dos oceanos, fluxos biogeoquímicos (ciclos de fósforo e nitrogênio),

4 https:/ / pt.unesco.org/courier/2018-2/um-glossario-o-antropoceno 
mudança no uso da terra (por exemplo, o desmatamento), uso global de água doce, concentração de aerossóis atmosféricos (partículas microscópicas na atmosfera que afetam o clima e os organismos vivos), mudanças no uso dos solos e introdução de novas entidades (por exemplo, poluentes orgânicos, materiais radioativos, nanomateriais e micro-plásticos) (MIRANDA et al, 2018, p. 1994).

Enquanto problemática integral da Educação Ambiental (EA) a Educação em Ciências possui certa responsabilidade social em atrelar o conhecimento científico junto aos LP e criar estratégias para abordar, contextualizar e contribuir para lidar com a problemática do Antropoceno.

Esses limites demonstram a capacidade que alguns modos de vida humanos, junto ao CMI de produção e consumo, possuem de alterar e modificar a estrutura biogeoquímica e termodinâmica do planeta. Com a disseminação de artefatos científicos e tecnológicos, a formação da era industrial, no século XVIII, o fim da segunda guerra mundial e a grande aceleração, o Antropoceno emerge (MIRANDA et al, 2018). A natureza se tornou uma fonte, infelizmente barata, de obtenção de lucro e consequentemente, de dilatação de desigualdades sociais, ou seja a problemática vai além de compreender questões científicas e tecnológicas, pois elas reverberam nas instâncias sociais e subjetivas e demandam ações que sirvam de antídoto ao Antropoceno.

Nesse sentido, conhecer e compartilhar ofícios de mulheres com seus saberes populares, tradicionais e "mágicos" pode oferecer outros modos de existir, ensinar e aprender ciências frente a de exploração de si e da natureza. Diante de tal problemática ambiental e social, é necessário encontrar estratégias nas educações para a ciência, para promover espaços de enfrentamento ao colapso ambiental, social e subjetivo.

O sujeito contemporâneo, aquele que encontra-se "voltado narcisicamente ao desempenho" (HAN, 2017, p. 10), em busca da 
promessa de progresso, desenvolvimento e resultados satisfatórios, que aliás, são alguns dos objetivos da ciência moderna, afunda-se em uma “depressão do sucesso" (HAN, 2017, p. 11). E é a mitologia de Eros abre espaço para a experiência daquele que não pode ser abarcado por vias narcísicas, pelo regime do eu: o outro. Eros nos serve para pensar na alteridade, em um mundo comum, constituído por nós, onde todos e todas que consomem e produzem resíduos são responsáveis pelo advento do Antropoceno.

\section{Eros como modo de repensar as educações para ciência na contemporaneidade}

Eros enquanto possibilidade de experenciar o outro em sua alteridade (HAN, 2017), modus operandi do feminino, que passa por homens e mulheres e outros devires, é uma via para pensar na problemática do Antropoceno, algo próximo a revolução do feminino, do deslocamento da figura central do anthropos, que preze por camadas coexistentes de vidas. As mulheres, historicamente no mundo ocidental, possuem a subjetividade, o corpo, em categorias que não faziam parte de certas políticas, a exemplo, na polis, que eram parte do terceiro escalão. Os modos de existir e resistir da mulher foram e são disputados ao longo da história, nas dinâmicas da modernidade junto a outras lutas étnicas, raciais, de gênero, sócias, que buscam viver a diversidade.

Dessa forma, é importante nos questionar qual história da ciência ensinaremos e conduziremos a ser escrita? Quais registros estamos deixando inscritos nessa vasta casa comum, a qual denominamos de natureza? Seria o mito do progresso a imagem da exaustão da natureza? Como ensinamos ciências na emergência do Antropoceno? Ou ainda, qual ciência ensinamos nesse momento histórico e geográfico em que nossas ações sob e no planeta produzem diversas crises e impactos: ambientais, sociais e subjetivos? De qual modo podemos, por meio da educação em ciências, encurtar esse espaço do Antropoceno? 
Tais preocupações inserem-se na necessária discussão para e por educadores das ciências, os responsáveis por mediar conhecimentos específicos da ciência às demandas pedagógicas e socioambientais. Para tatear reflexões para estas questões, que estão longe de serem respondidas, nos debruçamos em dissertar a respeito dos diálogos epistemológicos do Antropoceno para o Ensino de Ciências por meio da articulação de Eros e das narrativas de vidas de mulheres.

Eros, o mais antigo dos deuses, que para o filósofo Byung-Chul Han, em seu livro "Agonia de Eros" (2017), aponta para pensar a alteridade desterritorializada do capitalismo, desloca, a fim de submeter a diferença ao consumo, metáfora para conceber uma relação assimétrica com o outro. Ainda para o autor, na doutrina platônica de Eros, "a alma impulsionada por eros produz coisas belas e sobretudo ações belas" (p.75), entretanto, nesta sociedade atual, em que o desempenho e o cansaço produzem sujeitos isolados em si mesmos, é tarefa difícil pensar em ações comuns e em vidas multiespécies (HARAWAY, 2019). A fim de pensar em ações que não estejam sideradas em si, mas que atuem nas relações assimétricas com o outro, ou seja, ações que não sejam apenas de consumo das diferenças, é que pensamos em Eros como modo de repensar as educações para ciência no Antropoceno.

Vale ressaltar que, quando mencionamos o outro, compreendemos tanto humanos e não-humanos, dessa forma a preocupação com as educações para ciência é em introduzir a dimensão ética de Eros como forma de alteridade. Esse pensamento busca criar linhas de fuga para educações com fins mercadológicos, narcisistas e antropocêntricos. Junto à erosão que as ações humanas provocam na estrutura da Terra, em termos bio-geo-físicos-químicos, há também, a erosão do outro, a eliminação de tantas outras formas de vidas, por meio do consumo de vidas humanas e não humanas, metamorfoseadas em objetos de consumo.

Dessa forma, o docente, enquanto um mediador, ator social, tem como desafio apresentar e ensinar os conteúdos da ciência, uma vez que 
aprender é muito mais do que conhecer os mecanismos e as lógicas dos saberes das Ciências Naturais. Saber ciências envolve também, relacionar o conhecimento com problemáticas subjetivas, sociais e ambientais, a fim de desenvolver sensibilidades e autonomia na tomada de decisões políticas, frente às necessidades e demandas do Antropoceno.

Como divulgadores e porta-vozes da ciência, do conhecimento científico, professoras e professores possuem o desafio de articular saberes a diversos conhecimentos de várias áreas, como sociologia, filosofia, biologia, geografia, história, arte, áreas que permeiam o Antropoceno. Além disso, relacionar tais saberes às imbricações dessas áreas nos dilemas provocados por avanços na Ciência e Tecnologia (C\&T).

O desafio docente pode abranger também, problemáticas que pululam nos anseios individuais e coletivos dos alunos e incorporar essas demandas em suas pedagogias. Como exemplo de abordagem de temáticas há os estudos envolvendo Ciência, Tecnologia e Sociedade (CTS). No período pós Segunda Guerra Mundial o movimento CTS ganha espaço quando a sociedade passa a questionar certos discursos duvidosos, como a promessa de progresso e desenvolvimento, oriundos da C\&T. Concomitante, o movimento ambientalista realiza suas críticas a respeito do desenvolvimento do setor econômico por meio da exploração exacerbada dos recursos naturais, humanos e não humanos.

Elucidar e discutir questões ambientais, sociais e subjetivas no Antropoceno, vai além de explorar as relações CTS, oriundas do "progresso" da ciência na recriação, modificação e exaustão da natureza. Esta é uma questão pungente em tempos de carência de Alfabetização Científica (CHASSOT, 2001).

Uma forma de resistir a Agonia de Eros, a erosão do outro, é considerar os saberes populares, tradicionais, regionais, localizados e a partir disso ensinar e aprender ciências (CHASSOT, 2011, HARAWAY, 1995). Eros enquanto a capacidade de existir com o outro, em 
movimento contemplativo e cosmopolítico, de conexão com a terra e com as multiespécies. Uma das formas de resgatar os saberes populares é atrelar concepções da magia e do animismo, propostas de reconexão com o meio natural e possíveis respostas ao Antropoceno.

\section{A magia e o animismo como pulsos eróticos na disputa das educações para ciência}

Isabelle Stengers (2015) nos incita a pensar em modos de resistir à barbárie dos tempos atuais. A autora entende por barbárie o momento em que é necessário suscitar perplexidade ou incômodo diante do acontecimento em relação a exploração descontrolada dos usos e recursos da Terra. Ela discorre ainda, a respeito das consequências dessa exploração como uma intrusão à Gaia, e que é preciso (re)aprender a arte do cuidado com nosso planeta. E nesse sentido, pensar Eros, metaforicamente, é criar respostas a esse momento atual. Como propõe Stengers (2015, p. 35), "aquilo para o que temos que criar uma resposta é à intrusão de Gaia". Gaia é entendida pela autora como um outro modo de conceber o espaço geográfico e também, político e científico. Enquanto autorregulada, em relação às mudanças e alterações na termodinâmica da Terra, Gaia pode buscar um outro estado de regulação termodinâmica, que poderá ser favorável a algumas espécies e a outras não. Ou seja, nossas atividades de produção, consumo e gestão de resíduos, deverá ser pensada junto à intrusão de Gaia, como possível resposta ao Antropoceno, em suma, uma resposta a nós mesmos. E é nesse sentido que o animismo e a magia podem ser formas de produzir reconexões com o ambiente, com o outro.

Nas ciências da natureza o método cientifico envolve uma série de variáveis controláveis que possibilitaram alguns benefícios do mundo moderno, como os meios de transporte, fármacos que aumentaram a expectativa de vida, alimentos em larga escala. Entretanto, como aponta Starhawk (2018, p. 54) "uma das falhas da ciência é pressupor que só se pode entender o mundo por meio dela", 
segundo a autora, há algo a mais, "uma percepção e uma conexão mais profunda com a vida e a Terra" (STARHAWK, 2018, p. 54). A magia seria um caminho possível para ouvir a natureza e se comunicar com ela, ou seja, de ecoar outras narrativas no Antropoceno. Próximo a uma ética bruxa, uma vez que a perseguição às bruxas representa a caça de saberes populares, tradicionais, femininos de expropriação de terra e de conhecimentos. Dizer que um saber é mágico, ou das bruxas, é atribuir um valor para além dos usos da natureza para fins utilitaristas e mercadológicos.

Nesse sentido, resgatar os saberes populares (CHASSOT, 2001), reativar o animismo (STENGERS, 2017), criar conexões rizomáticas para além das generalidades, estão para a magia, que segundo Isabelle Stengers (2017, p. 14), é “uma operação rizomática”, pois necessita de conexões com outros ofícios para se manter distante dos poderes de julgamento "que exige que decidamos se somos herdeiros das bruxas ou dos caçadores de bruxas" (STENGERS, 2017, p. 15).

Nesse cenário de reativar o animismo, a magia e realizar arranjos multiespécies, Anna Tsing (2019) chama atenção para o modo como os não humanos (as outras espécies vivas, bem como não vivas, o dióxido de carbono, radioatividade, plásticos) respondem às atividades humanas e compõem a paisagem do Antropoceno. A autora aponta que o que chamamos de pragas, é, em seu entendimento, organismos que disputam o controle após intervenção humana de modo a "entrelaçar histórias humanas e não humanas" (p. 241). Anna Tsing, assim como Donna Haraway (2019), busca retirar a centralidade do humano, nos convidando a pensar em processos sociais mais amplos, que dilatem as visões de cultura e política mais que humanas, junto ao "desafio de sobreviver ao Antropoceno" (TSING, 2019, p. 265) e agenciar técnicas, práticas e políticas em conexão com o planeta Terra.

São com as mulheres, com a força do coletivo, das pulsões de vida e de Eros que pensamos em respostas à intrusão à Gaia; ações nesse tempo do Antropoceno. 
O conhecimento de técnicas, práticas e políticas realizadas por mulheres como formas de resistir a agonia de Eros, ou seja, a narcisificação do si

Por meio de relatos de vida de mulheres, suas histórias mostraram um outro modo de lidar com o corpo, a natureza, a economia e os saberes científicos/químicos, e podem ser atrelados ao Ecofeminismo, uma vez que a reflexão de gênero e o pensamento ecológico são indispensáveis para pensar nos desafios do século XXI (PULEO, 2011). Essa perspectiva visa a superação de visões simplistas, como o dualismo natureza-cultura, por meio do debate feminista e ecológico para tratar das divergências da associação da mulher à natureza (DI CIOMMO, 1999).

As pesquisas narrativas também remetem à imagem das mulheres bruxas da Idade Média, donas de seus saberes, parteiras, curandeiras, tintureiras, químicas que cultivavam a arte do cuidado com seus corpos, com a natureza da qual fazem parte e o domínio do feminino, dividindo e multiplicando seus conhecimentos (FARY; SAVIOLI, 2020).

Dessa forma, por meio de pesquisas narrativas com mulheres, que possuem seus ofícios alinhados à Gaia, ou seja, com baixo impacto ambiental, temos como exemplos de ações no Antropoceno: i) cosmetologia natural; e ii) agroecologia, modos de resistir a Agonia de Eros (HAN, 2017), a erosão do outro no Antropoceno.

As narrativas de vida que versam a respeito da cosmetologia natural mostram, por meio do autocuidado e da autonomia nos cuidados com higiene e corpo, um modo de produzir saberes de forma conectiva, sem poluir o corpo e o restante do meio natural. Visto que a maior parte dos cosméticos possuem uma lista de ingredientes, muitos em códigos, com grau de toxicidade e poluição, como por exemplo, os polímeros sintéticos - os plásticos, oriundos do petróleo, uma fonte não renovável de energia. Além disso, produzir e consumir cosméticos 
naturais é uma forma de resistir às capturas da subjetividade capitalista em relação a indústria e o mercado da beleza.

Já as histórias a respeito da agroecologia apontam para uma composição com Gaia, um modo de produzir alimentos que auxilie a reverter os efeitos do Antropoceno, no que tange aos LP referentes aos fluxos biogeoquímicos (ciclos de fósforo e nitrogênio), mudança no uso da terra, mudanças no uso dos solos e introdução de novas entidades, a exemplo das consequências dos usos de agrotóxicos em monoculturas.

As mulheres, outra característica que relaciona a caça às bruxas, tem conexão com a depredação do meio ambiente, exploração capitalista da natureza e das mulheres (FEDERICI, 2017). Ou seja, há nessas narrativas um modo de produzir ciência, outra epistemologia para compreensão do fazer ciência e outra ontologia presente nesses modos de vida. Além disso, elas criam linhas de fuga, fraturas em relação ao capitalismo, ao controle científico e biológico. Talvez, então, essas mulheres façam muito mais do que ciência, façam magia (STENGERS, 2017; STARHAWK, 2018). E nossa responsabilidade, enquanto mulheres, professoras e pesquisadoras, é narrar esses saberes e modos de vida para as interlocutoras e interlocutores nas educações para a ciência, uma vez que a Educação é um dos pilares que constitui a sociedade.

\section{Conclusão}

Assim, suscita-se uma espécie de incômodo necessário diante da exploração descontrolada dos recursos da Terra, e da eliminação do outro, que também promove um espaço para rever, repensar e questionar a ideia de desenvolvimento e crescimento científico e econômico, no Antropoceno. Os eixos abordados contribuem para refletir nos processos de aprender e ensinar outros modos de consumo de si, do outro, e da natureza, além de buscar mudanças nos modos de conceber o mundo por meio da educação em ciências. Um mundo em que humanos, animais, consciência, desaguam uns nos outros. Como 
resultados, mostra-se o cuidado com a natureza, com o outro, por meio da força do feminino, do coletivo, contribuindo para refletir nas educações para a ciência na era do Antropoceno. É necessário dilatar nosso entendimento político, social, econômico, ambiental e educacional, se quisermos sobreviver e garantir um mundo com pulsões de Eros. Essa garantia ocorre a partir do momento em que saímos do inferno do igual, uma vez que o desaparecimento do outro fornece indícios de uma sociedade que caminha para vias narcisistas (HAN, 2017).

\section{Referências}

CHASSOT, Attico, Alfabetização científica: questões e desafios para a educação. Ijuí: Ed. UNIJUİ, 2001.

CRUTZEN, Paul. Geology of mankind. Nature, 2002.

CRUTZEN, Paul. J.; STOERMER, Eugene. F. The Anthropocene. Global Change Newsletter, n. 41, p. 17-18, 2000.

DANOWSKI, Deborah; VIVEIROS DE CASTRO, Eduardo; LATOUR, Bruno. Position Paper: The Thousand Names of Gaia. From the Anthropocene to the Age of the Earth, 2014.

DI CIOMMO, Regina Célia. Ecofeminismo e educação ambiental. Uberaba: Editora da Universidade de Uberaba; São Paulo: Conesul, 1999.

FARY, Bruna Adriane; SAVIOLI, Angela Marta Pereira das D. As bruxas da contemporaneidade: técnicas, práticas e políticas para o ensino de química. In: VIENA et al (Org.). Pesquisa, gênero $\mathcal{E}$ diversidade: memórias do III Encontro de Pesquisa por/de/sobre Mulheres. Curitiba: Íthala, 2020.

HAN, Byung-Chul. Agonia de Eros. Petrópolis, RJ: Vozes, 2017.

FEDERICI, Silvia. Calibã e a bruxa. Mulheres, corpo e acumulação primitiva. Trad. de Coletivo Sycorax. São Paulo: Elefante, 2017.

GUATTARI, Félix. As três ecologias. Tradução de Maria Cristina F. Bittencourt. Campinas: Papirus, 2012. 
HARAWAY, Donna. Anthropocene, Capitalocene, Plantatiocene, Chthulucene: Making Kin. Environmental Humanities, 6, p. 159-165, 2015.

MIRANDA, J. L. et al. O Antropoceno, a Educação Ambiental e o Ensino de Química. Revista Virtual de Química, v. 10, n. 6, p. 1990-2004, 2018.

PULEO, Alicia. Ecofeminismo para otro mundo posible. Madrid: Cátedra, Colección Feminismos, 2011.

RAGO, Margareth. A aventura de contar-se: Feminismos, escrita de si e invenções da subjetividade. Campinas, SP: Unicamp, 2013.

ROCKSTRÖM, J., STEFFEN, W., NOONE, K. et al. A safe operating space for humanity. Nature, v. 461, p. 472-475, 2009.

STARHAWK. Magia, visão e ação. Revista do Instituto de Estudos Brasileiros. Brasil, n. 69, p. 52-56, abr. 2018.

STENGERS, Isabelle. Reativar o animismo. Trad. Jamille Pinheiro. Chão de Feira: Belo Horizonte, 2017.

STENGERS, Isabelle. No tempo das catástrofes - resistir à barbárie que se aproxima. São Paulo: Cosac Naify, 2015. 